\title{
La gestión de las marcas y los valores en el turbulento contexto de la comunicación
}

The Management of Brands and the Values in the Complex Context of Communication

Dr. Juan Benavides Delgado Universidad Complutense

juanbenavides@ccinf.ucm
Benavides Delgado, J. (2017)

La gestión de las marcas y los valores en el turbulento contexto de la comunicación

Revista Internacional de Investigación en Comunicación aDResearch ESIC. № 16 Vol 16

Segundo semestre, julio-diciembre 2017 · Págs. 34 a 59 DOI: 16.7263/ADRESIC.016.002 
RESUMEN

Clasificación JEL:

M14, M37

Palabras clave:

Valores,

marca,

comunicación,

publicidad,

ética,

empresa,

negocios

El presente artículo hace un breve repaso de las principales cuestiones que afectan a la gestión de la marca en un mercado progresivamente globalizado muy cambiante y lleno de conflictos. La introducción del valor en la gestión de la marca ha complicado todavía más las acciones de comunicación porque introduce contenidos y modelos de gestión que no siempre cabe comunicar a través de las herramientas tradicionales de la comunicación de marca. El valor exige nuevas formas de pensar la comunicación y nuevos modelos que requieren el compromiso de la política y del conjunto de la sociedad. Este valor expresa la necesidad de un nuevo paradigma que exige pensar de otra manera la empresa y el universo corporativo.

\section{ABSTRACT}

\section{JEL Classification:} M14, M37

Key words:

Values,

brand,

communication, advertising,

ethics,

institutions,

business
The present article gives a brief summary of the main factors that affect brand management in an increasingly globalized, highly unstable and conflictive market. The inclusion of a «value concept» into the brand management has further complicated communicational matters, mainly because ithas introduced contents and management models that cannot always be communicated by use of traditional branding tools. The value demands not only new ways of thinking about communication but also new models that require commitment of both political institutions and society as a whole. This value expresses the necessity of applying a new paradigm that implies a change in the way we understand business and the universe of corporate communications. 


\section{Aspectos previos}

Hace algo más de tres años terminaba un largo artículo y un poco después un segundo trabajo donde pretendía resumir la situación en la que se encontraba la marca (J. Benavides Delgado, 2013 y 2015). Había entonces una preocupación fundamentalmente terminológica y la investigación sobre la comunicación de la marca celebraba el éxito del proceso de construcción de la marca corporativa iniciado bastantes años atrás. Desde ese momento, en la investigación de la comunicación, la marca de producto tenía ya su referente paralelo en los valores (intangibles) de la compañía que eran expresados por la marca corporativa; con ello se estableció una tipología donde la comunicación de producto expresaba los atributos de éste y los valores de consumo asociados y, a su vez, la comunicación corporativa hablaba de los valores relacionados con la compañía y sus formas de relación con el conjunto de la sociedad. Así al menos lo subrayaban algunas de las conclusiones de los trabajos a los que acabo de hacer referencia; unas reflexiones que brevemente resumo en tres principales:

- La primera que la marca se debe observar como un signo de representación de los productos, servicios y de la propia empresa; una representación que circula de una forma poco controlable en los contextos y discursos sociales que en la actualidad experimentan un cambio permanente. La marca es la consecuencia de un proceso de construcción social de indudable alcance cognitivo, que expresa la naturaleza de los contextos culturales de donde surge. La circulación de las marcas (ver Esquema 1), tanto de de producto como corporativas (además de los que significa

\section{Esquema 1}

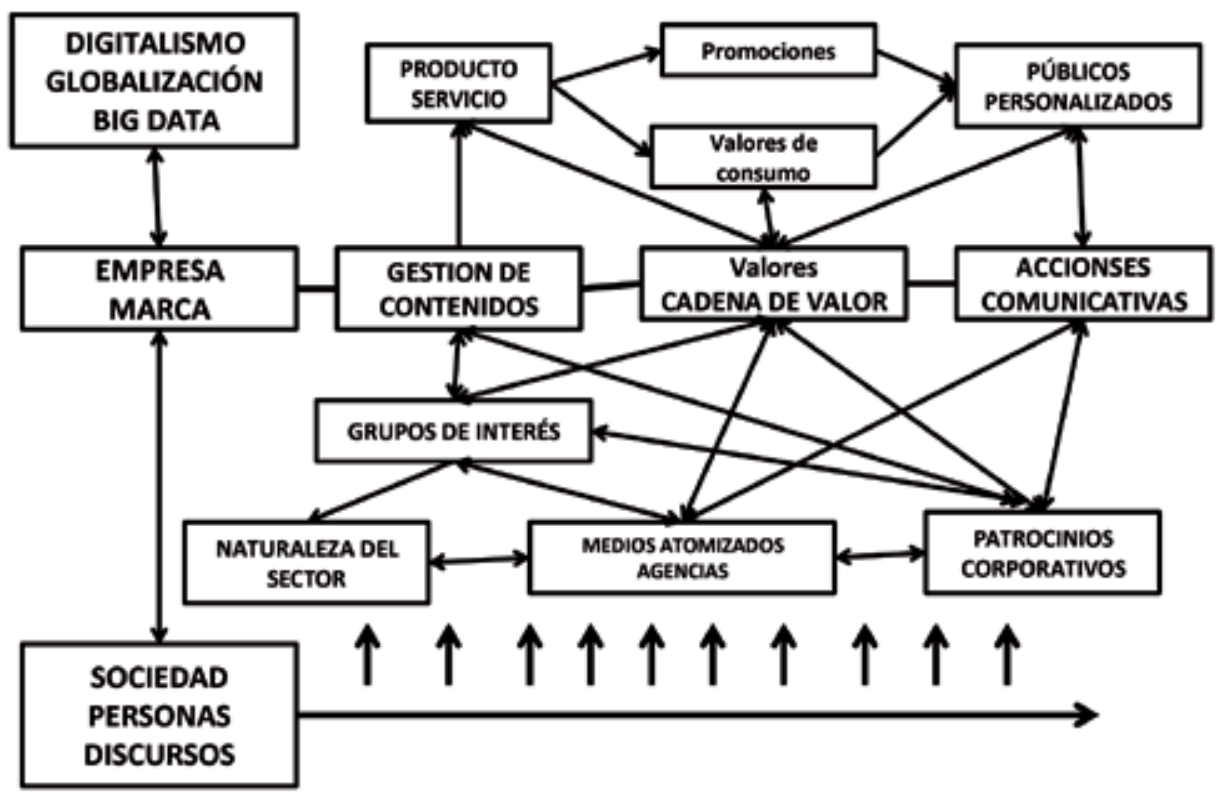


la propia empresa como valor) requieren de una definición e investigación más precisa atendiendo a la multiplicación de los diversos referentes donde intervienen de forma determinante los diversos procesos comunicativos: grupos de interés de la empresa, atomización de los medios, agencias, formatos y plataformas utilizadas y, especialmente, la gestión de contenidos y fragmentación de los discursos sociales y personales de los consumidores sobre los que se proyecta las marcas ${ }^{1}$.

Esquema 1: Los referentes que determinan la circulación de la marca afectan a muy diversos factores que se ubican en un proceso permanente de cambio social. El eje vertebral de la empresa y la comunicación de marca se configura a través de la gestión de los contenidos, la definición y posicionamiento de la cadena de valor, los grupos de interés y las acciones comunicativas que se establezcan.

El proceso citado en el Esquema 1 ha sido observado en dos recientes investigaciones donde la relación de la empresa con los procesos de comunicación vienen muy determinados por el eje vertebral de su estrategia comunicativa: la gestión de los contenidos y los valores asociados a los productos, servicios y la propia empresa; sin esa estrecha relación no cabe conseguir un contacto emocional y eficaz con los públicos consumidores (Ver VVAA, 2016b y J .Benavides Delgado, 2017).

- La segunda conclusión se concreta en los propios espacios sociales donde circulan las

\footnotetext{
1 Este tema de la circulación de la marca es muy importante porque la marca se posiciona discursivamente en contextos sociales muy diferentes que no dependen ni cabe controlar desde los emisores sociales o desde la planificación estratégica que estén aquellos en condiciones de elaborar. A ello me refiero, por ejemplo, con la noción de umbral corporativo que es de naturaleza estrictamente cognitiva (J. Benavides, 2013, p. 530).
}

marcas; estos espacios son de naturaleza cognitiva, lo que significa que la marca no está sólo en el mercado sino especialmente en la cabeza de las personas. Sin duda, este enfoque obliga al investigador a situarse bastante más allá de las tradicionales nociones de personalidad de marca o las clásicas categorías de visión y misión de una empresa; son enfoques que no dejan de ser útiles como categorías funcionales que permiten a los emisores corporativos construir y establecer en sus mensajes rasgos de identidad, pero poco más si queremos determinar la ubicación cognitiva de sus marcas en sus procesos de circulación social.

- La tercera se refiere al hecho mismo de lo que significa la comunicación del propio valor y de los contenidos que de ahí se derivan; un proceso que tiene su origen en el consumo del producto, — cuando la comunicación de sus atributos cede su lugar a los valores asociados a su consumoy termina en la comunicación de la propia compañía. Cuestiones, todas ellas, que exigen profundizar, con el mayor detalle posible, lo que hay detrás de los estilos de vida de las personas, las tendencias sociales y la naturaleza y gestión interna de las organizaciones e instituciones sociales. El valor se convierte en el eje central de la comunicación.

Sin embargo la evolución del mercado en esto últimos años sigue siendo muy rápida y vertiginosa y no parece que las investigaciones que seguimos realizando en esto de la marca y la comunicación expresen una situación de calma y armonía ${ }^{2}$. Lo que parece claro es que el espacio cognitivo de la marca y la importancia decisiva dada al valor han acentuado la importancia de la

2 Ver las investigaciones realizadas con la Asociación Española de Anunciantes durante los años 2015 y 2016 (ver Referencias Bibliográficas). 
llamada economía de la reputación, que no es otra cosa que la necesidad creciente de las empresas de evitar la caída de la credibilidad y la confianza social respecto a ellas. En un reciente informe, durante este último año continúa la pérdida de confianza generalizada, cayendo en los cuatro tipos de organizaciones que analiza el barómetro: empresas, gobiernos, ONG's y Medios de Comunicación. Una situación sin precedentes: el $52 \%$ de la población considera que el sistema no funciona (Approaching the Future, 2017, p. 8). Por ello mismo, la gestión de la marca no se enfrenta solamente a las cuestiones tradicionales derivadas de los productos sino las derivadas de algo tan abstracto como son los valores en un contexto progresivamente globalizado. Este hecho expresa la realidad de unas circunstancias extraordinariamente complejas y decisivas a la hora de poder evaluar lo que supone y exige a las empresas y sus marcas la gestión del valor en los procesos de globalización y revolución tecnológica. Esta situación obliga, a su vez, a redefinir problemas y cambiar enfoques, que es el objetivo central de este artículo.

Sin duda, las conclusiones que acabo de mencionar expresan tendencias en la investigación de la marca que todos los investigadores reconocen, —diciéndolo o sin decirlo_-, y que se concreta en la necesidad de hacer, respecto a la marca, un enfoque sistémico que nos ayude a comprender la comunicación de la marca y también de la empresa como una estrategia en red, donde cada elemento de un sistema se define por su relación con los elementos de ese mismo sistema y de este con otros sistemas. La estrategia y gestión de las marcas de la empresa vienen determinadas por esa red de relaciones especialmente entre lo diferentes stakeholders de importancia para la empresa y otros referentes sociales de dentro y fuera de la organización; precisa- mente donde se la juega el llamado por muchos link emocional entre la marca y el cliente entendida ya como grupo de interés (VVAA, 2016b, pp.28 y ss.). Con ello, el problema de la marca es, sobre todo y fundamentalmente, una cuestión de gestión que debe ayudar a comprender en cada momento el lugar que ocupan los productos, los grupos sociales, las personas y las organizaciones en un circuito que no controla nadie.

\section{La gestión funcional y estructural de las marcas en el contexto de la comunicación}

De todo este conjunto de conclusiones derivan dos nuevas exigencias: la primera que no cabe ya hablar solamente de la naturaleza de una marca sino de la forma en que ésta es gestionada, su posicionamiento social y el lugar que ocupa en los espacios cognitivos y, la segunda, el papel que en cada momento adquieren los valores de la marca en relación con la empresa y con el conjunto de sus grupos de interés. Estas dos cuestiones suponen una diferencia en la gestión, pero no tanto una diferencia en la naturaleza de la marca de que se trate, sea ésta de producto o corporativa, sino una distancia que perfile y defina lo que es y hace la comunicación de la marca y lo que es y debe hacer la empresa. Dos tipos de gestión que me permitía diferenciar entre los aspectos funcionales de la propia comunicación, - lo que se pretende conseguir en el corto plazo y que afecta sustancialmente al modelo de negocio-, y los aspectos estructurales, que atienden al largo plazo y a la naturaleza y ser de la propia organización.

Resulta evidente que hay marcas, cuya naturaleza y simplicidad no les permite ir más allá de su pura funcionalidad en la presencia de acciones promocionales de productos o servicios; también hay otras marcas de producto, que sin dejar de hacer acciones promocionales, trabajan con valo- 
res, situados más allá de los aspectos tangibles de un producto o de un servicio y referidos a estilos de vida y modelos de comportamiento social. Del mismo modo, las marcas corporativas realizan un papel muy similar, tanto en la promoción de los valores de la compañía como en la construcción de aquellos valores que se suponen estructuran y definen a la propia organización. En ambos casos la gestión de estas marcas procura el mejor posicionamiento en los discursos sociales a través de mensajes donde su creatividad persigue el enganche emocional con los grupos sociales; y se hace tanto en la comunicación de las marcas de producto como las corporativas. prácticamente reducida a la gestión funcional de sus productos y valores asociados (sean éstos los referidos al propio producto o a la organización) porque la comunicación de la empresa se deberá dirigir probablemente a otros ámbitos de actuación.

Ahora bien si aceptamos esta diferencia la cuestión que no queda clara y debe estudiarse es la propia naturaleza de los valores que se comunican; porque, en efecto, promocionar los atributos de un producto o de un servicio es una cuestión clara y definida, de la misma forma que tampoco resulta difícil relacionar un producto con su valor de consumo o la propia

\section{Esquema 2 - La doble gestión del valor en la marca y la empresa}

1. Gestión Funcional: Este tipo de gestión afecta tanto al posicionamiento de productos, (atributos y valores de consumo), servicios como a los valores de una empresa expresados en su narrativa comercial y publicitaria. La naturaleza de esta gestión viene dada por las acciones comunicativas de naturaleza promocional y de imagen.

2. Gestión estructural: Este tipo de gestión afecta a la estructura de la organización: naturaleza de la compañía, sector y relaciones con los diferentes grupos de interés. La natrualeza de esta gestión viene dada por acciones comunicativas internas a la empresa o en acciones puntuales de comunicación externa.

El enfoque planteado en el Esquema 2 abre dos líneas divergentes en la gestión de la comunicación a través del valor; una primera que atiende directamente al valor de la marca de producto o corporativa (gestión funcional) y una segunda que afecta directamente al valor de la organización (gestión estructural) ${ }^{3}$. Esto significa, que la comunicación de la marca queda

3 En este punto marco una diferencia sustancial y doy un paso más respecto a lo indicado al final del artículo citado al principio (J. Benavides Delgado, 2013, pp. 534 y ss.) compañía a través de un conjunto de categorías de valor. Todo ello queda bien resuelto por la comunicación comercial y las acciones de patrocinio. Pero cuando el investigador se adentra en la naturaleza de los valores que se enumeran de una organización, su aplicabilidad y funcionamiento, la explicación es mucho más difícil. Por ello mismo, cuando las organizaciones comienzan a comunicar los modelos de gestión ética que aplican, muchas veces generan más desconfianza e incertidumbre de la que debieran, porque quizá las explicaciones que ofrecen 
exigen más desarrollo y profundidad que lo que son capaces de explicar las herramientas de la comunicación comercial y mediática. Este hecho se observa con claridad en las nuevas preocupaciones derivadas del llamado storytelling, que no es otra cosa que la necesidad que tienen las organizaciones de construir un nuevo relato de lo que son y significan en los nuevos y plurales contextos sociales.

En efecto; los modelos funcionales de gestión de las marcas son más cortoplacistas y atienden más directamente a los mensajes y estrategias más ocupadas de los modelos de negocio que persiguen retorno y eficacia. Sin embargo, cuando una organización quiere posicionarse a través de la transparencia, responsabilidad ética o en el cumplimiento de sus promesas o el ejemplo de su conducta la cuestión es más compleja y los mensajes al uso quedan cortos en credibilidad porque los significados de la gestión estructural del valor requieren un largo plazo y una comunicación que no cabe relacionar con el modelo de negocio y el retorno inmediato. Se requiere un tipo de gestión, donde la comunicación comercial y publicitaria apenas tiene sentido si no viene apoyada por otro conjunto de actuaciones. Sin duda la proliferación de Informes y publicaciones que las empresas y organizaciones multiplican desde hace unos pocos años son un ejemplo claro de esta nueva necesidad. Sin embargo, no parece que los tipos de Informes que habitualmente se hacen cubran las necesidades y exigencias de una sociedad progresivamente globalizada y harta de información. Incluso habrá que preguntarse si estos Informes son realmente conocidos por los públicos consumidores de las marcas de esas mismas organizaciones más allá de lo que pueda decirse en un titular de prensa o una noticia de alcance. Esta situación está abriendo una desconfianza, —no sé si es justa en todos los casos-, pero si añadida y extendida a los Informes, a sus autores y a los propios sistemas de medición y evaluación que se les aplica. Subrayo de nuevo que el eje del problema no reside tanto en el tipo de comunicación sino en la naturaleza del valor que se construye y el modo de gestionarlo y, en su caso, comunicarlo.

La comunicación funcional de las marcas (tanto de producto como corporativa) es un proceso que arranca de abajo-arriba, de menor a mayor complejidad. Efectivamente en ese proceso intervienen marcas de producto y corporativas pero el valor queda reducido a categorías de corto significado y equívocas expresiones determinadas por la creatividad y la retórica publicitaria. Por ello irealmente cabe hablar en la actualidad de una adecuada gestión estructural de la marca o es preferible hablar de otra manera, cambiar la terminología y no hablar, en ese caso, de marca sino, -lo acabo de decir-, de compañía o de organización? Resulta posible que este conjunto de circunstancias hayan acentuado la pérdida de confianza en una organización en lugar de potenciar la solidez y credibilidad de una compañía; y también es posible, que la percepción de este hecho haya conducido a la creciente preocupación por los contenidos y la emocionalidad a ellos asociada. Pero los cuestionamientos, que quizá haya que añadir a estas lógicas preocupaciones habrá que dirigirlos en otra dirección con preguntas sobre si las empresas y organizaciones tienen conocimiento real de la naturaleza y significados de los valores que utilizan y si son adecuadas las herramientas empleadas en la gestión y comunicación del valor. A mi modo de ver, aquí residen algunos de los problemas que explican la caída de la credibilidad y confianza en la gestión de las marcas y las organizaciones, $y$, en el fondo, del conjunto del sistema. 


\section{Esquema 3a · El proceso ascendente en la gestión: de la marca a la empresa}

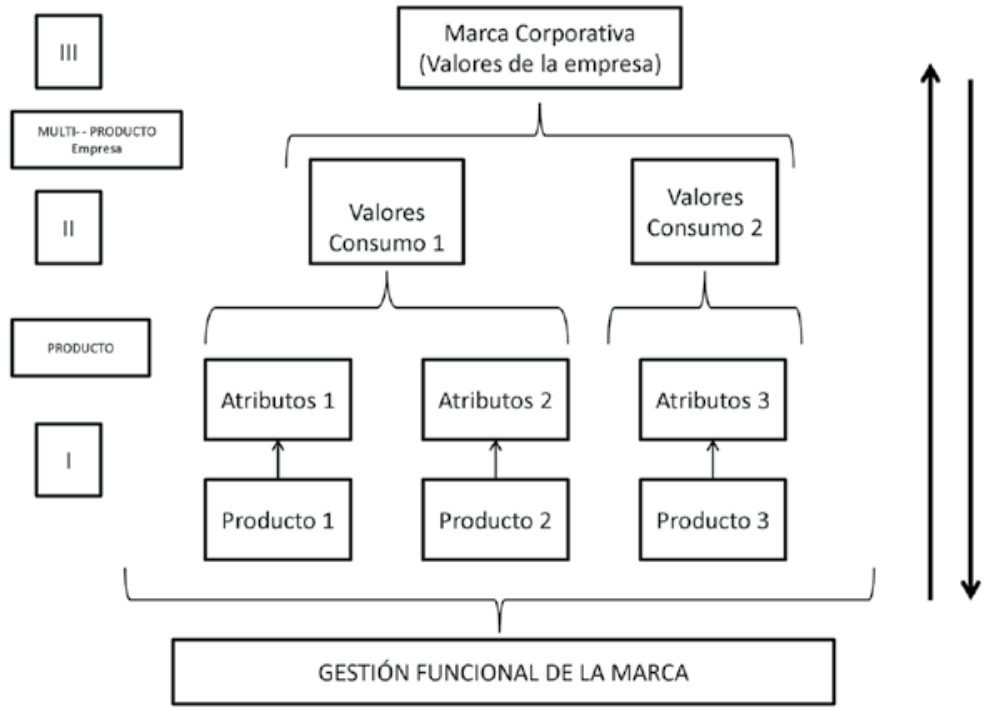

Esquema 3b - El proceso ascendente en la gestión: de la marca a la empresa

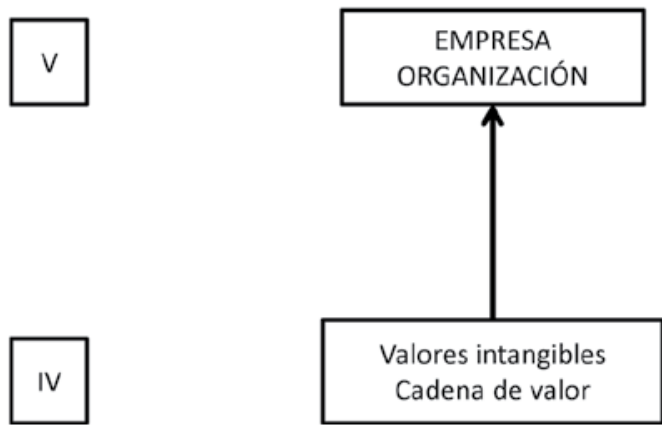

$$
\uparrow
$$


De acuerdo a lo indicado en los esquemas $3 a$ y 3 b el proceso en la gestión de la marca arranca de las posiciones de base de la comunicación comercial al uso donde las acciones promocionales y las acciones de valor se asocian muy directamente a las cuestiones de la oferta o de los contenidos que se estén en condiciones de poder explotar Son los niveles I-III (Esquema 3a) donde la marca se gestiona comunicativamente de un modo claro y preciso. Si continuamos con el proceso ascendente indicado ya en el Esquema 3b empiezan las complicaciones, porque la marca debería sustituirse por la propia empresa, pero lo normal es que las compañías construyan su marca corporativa al modo de un paraguas que explique y garantice la calidad de uno o varios productos, la naturaleza de su consumo y la propia credibilidad de la compañía; con ello todo queda situado en el mismo nivel III del Esquema citado. Es el caso de numerosos ejemplos de grandes y conocidas marcas de muy diversos sectores, donde el slogan de la marca se convierte no sólo en el garante del uso de un producto sino en la visibilidad de la organización que lo acredita. Lo que realmente complica, —cuando no impide- - la gestión estructural y el conocimiento real de los valores de la empresa que se comunica ${ }^{4}$.

A mi modo de ver ahí está el problema que determina y diferencia la comunicación de la marca de lo que debe ser la comunicación de la empresa que, por la propia exigencia de la complejidad corporativa, no puede reducirse a lo que expresa una acción promocional, un anuncio o toda una campaña donde la marca circula en muy diferentes niveles.

\footnotetext{
4 Son muchos los ejemplos que hemos estudiado y que sería prolijo citar en el presente artículo. En los comentaros que siguen se expresan algunos ejemplos.
}

Revisada la comunicación de en torno a 120 marcas $^{5}$ la práctica totalidad ejercen una gestión exclusivamente funcional de la comunicación de sus marcas sean éstas de producto o corporativas, atendiendo desde acciones promocionales y de patrocinio hasta la gestión de los valores de consumo y aquellos otros relacionados con la organización. Se cuentan muy pocas las compañías que procuran una comunicación más atenta a una gestión estructural de sus valores como organización. Como ya he dicho, la gestión funcional de las marcas supone una potenciación de los valores del producto o del servicio a través de la calidad del propio producto o la solidez dada por los valores corporativos relacionados con la compañía; nada más. Es una gestión cuya finalidad de posicionamiento más clara es la de situar al producto o el servicio en una permanente línea promocional y relacionar este espacio de consumo con el modelo de negocio de que se trate. El modelo de negocio es casi siempre el único y exclusivo referente. Con ello se potencia el modelo de negocio y se da a la marca la fuerza de lo que puede significar el conjunto de la compañía, pero con ello no se aumenta necesariamente la credibilidad y la confianza y todavía menos el conocimiento de lo que es la organización y el papel que ocupa en la sociedad donde opera. La mayoría de las empresas han organizado y gestionado su marca corporativa en relación con la comunicación del producto o del servicio y su proyección expresiva ha sido, casi siempre, hacia fuera, de acuerdo a la comunicación comercial más tradicional; pero se olvida que la empresa no es un producto sino algo mucho más complejo a lo que la sociedad exige claridad y ejemplo. Parece cierto que hay compañías (Ver Esquema 4) que procuran introducir en su comunicación cierta gestión estructural, -construyen por así decir y de forma simultánea una gestión doble: funcional/estructural-, pero muchas veces esa buena intención puede aumentar la desconfianza social y percep-

\footnotetext{
5 Seguimiento realizado en estos tres últimos años de la publicidad, patrocinio corporativo, acciones sociales, etc. de un conjunto de marcas, así como su presencia en medios digitales, webs corporativas y el conjunto de informes que se publican a lo largo del año.
} 
ciones equívocas porque lo que la empresa dice se comprende como si fueran anuncios. Se confunden dos gestiones que probablemente exigen estrategias de contenidos muy diferentes. Es muy posible que este sea el problema fundamental.

Hace unos pocos párrafos me refería a esta cuestión comentando la redacción de Informes que ocupan una importante presencia en algunas compañías, pero cuyo conocimiento probablemente no alcance al conjunto de la sociedad o viene muy determinado por el propio mo- delo de negocio o reducido al lenguaje gremial de algunos grupos de interés. No cabe duda de que el sector es muy determinante en la toma de decisiones a la hora de gestionar la comunicación; el sector de gran consumo parece que está más obligado al producto que el de servicios, el financiero o el retail. Pero esta circunstancia dificulta, en la misma medida que sucede en otros sectores, la construcción del valor a la que se obliga la empresa respecto a las exigencias sociales; y ahí comienzan los problemas.

\section{Esquema 4 - La marcas solamente se gestionan de modo funcional (algunos ejemplos) ${ }^{6}$}

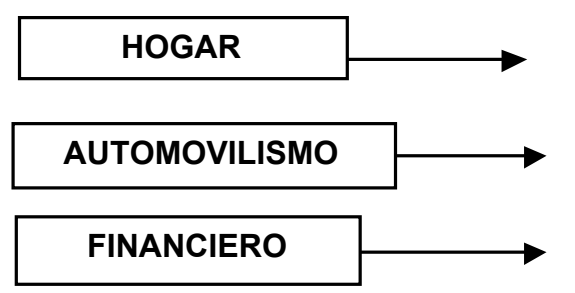

ALIMENTACIÓN
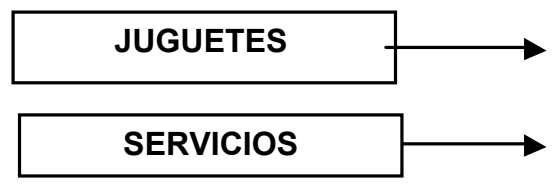

TECNOLOGÍA

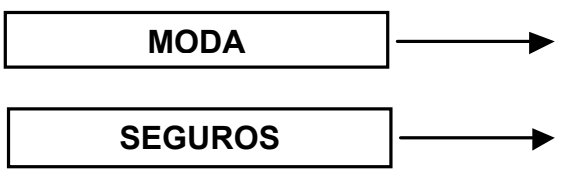

Funcional/Estructural: Ikea, Leroy Merlin. El Corte Inglés

Funcional: Audi, Mercedes.

Funcional/Estructural: BBVA

Funcional: ING Direct, SANTANDER.

Funcional: DIA, Carrefour. CAMPOFRIO, DANONE. Leche Pascual.

Funcional: Mattel

Funcional / Estructural: Lego

Funcional: Starsbucks, McDonald's.

Funcional: Samsung, Phillips, Movistar, Amazon, Google...

Funcional/Estructural: Telefónica.

Funcional: Pikolinos, Budberry, Abercrombie...

Funcional/Estructural: MAPFRE, MUTUA.

6 Desde estas páginas agradezco la colaboración de la investigadora Dra. Estrella Barios de la Universidad Autónoma de Barcelona en la revisión y análisis de diversas marcas. 
Como ya he indicado, cabe observar en algunas marcas un enfoque comunicativo del valor si bien la determinación del producto viene dado por la gestión directa de los contenidosolapromoción de nuevos modelos de comportamiento y expresión de un estilo de vida o un modo de pensar ${ }^{7}$. Pueden servir también de ejemplo algunas otras marcas del sector del hogar o de los seguros, donde los valores relacionados con algunos de sus grupos de interés (clientes, proveedores, etc.) cobran una especial y puntual relevancia en el propio posicionamiento de los servicios de la marca. Pero esta circunstancia explica que cualquier valor corporativo siempre queda constreñido a la marca y la determinación de ésta respecto al producto o el servicio es tan fuerte que la compañía queda excesivamente sujeta a las herramientas expresivas de la marca. De modo parecido, otras empresas especialmente del universo norteamericano, que también gestionan su marca de modo exclusivamente funcional -pegadas a su producto y servicios - asocian sus valores a aspectos relacionados con los clientes y la naturaleza aspiracional de sus consumidores o perfiles de públicos más directos. Es el caso, por ejemplo, de la marca de moda Abercrombie o de las compañías tecnológicas como Amazon o Apple; la idea de exclusividad o liderazgo elude en muchos momentos la publicidad comercial tradicional centrando su comunicación en los puntos de venta de sus locales enfocando sus productos hacia un modo específico de entender la belleza del cuerpo (Abercrombie) o construyendo una marca multiproducto enfocada hacia un cliente construido a partir de sus estilos de vida, lo que permite situar a la empresa en la vanguardia de la innovación y la modernidad (Amazon, Apple...). Pero detrás de todos esos ejemplos, la empresa permaneceoculta, no pudiéndose hablar de una comunicación de los valores de la compañía. El liderazgo de la empresa se centra exclusivamente en su modelo de negocio y su etiqueta de lovemarks es un conseguido producto del marketing de toda la vida y nada más.

7 Es el caso, por ejemplo de las últimas campañas de CAMPOFRIO o IKEA.
Desde la perspectiva aquí apuntada, cabe concluir que las marcas, —sean éstas de producto o corporativas-, solo se gestionan funcionalmente. Lo que al principio de este artículo he definido como gestión estructural es casi un sofisma o las Noticias de Ninguna Parte, por citar el titulo del conocido y antiguo escrito de W. Morris. Esta situación expresa, a mi modo de ver, la comunicación equívoca o engañosa en que muchas veces se convierte la comunicación de la marca y la propia gestión de los valores asociados a la empresa o la organización; produciéndose en algunos momentos una cierta distorsión entre lo que significa la comunicación de la empresa asociada con su modelo de negocio, - que debe proteger y en su caso potenciar-, con la empresa relacionada con lo que debe ser como organización y la coherencia expresada en sus modelos de comportamiento respecto al contexto social que ocupa.

La marca no puede sustituir a la compañía y menos todavía convertir la organización en un producto; y si acaso hablamos de que la marca potencia o enriquece la organización, se me ocurre que habrá que hacerlo con otras herramientas comunicativas. Porque de lo contrario, además de un signo, la marca se convertirá en un constructo engañoso, que puede generar respecto a la empresa más des-legitimidad social que otra cosa, —que es lo que entiendo está ocurriendo en muchos casos- Hago estos últimos comentarios porque estos nuevos aspectos del valor requieren de todo un conjunto de herramientas que no cabe introducir en la propia gestión funcional de la marca sino en otros ámbitos de trabajo de la compañía. Quizá la gestión estructural

8 Por ejemplo, resulta muy común debatir en torno a los valores y activos de la marca en el sentido de entender la marca como suministro constante al valor de la organización (D. Aaker, 1991); pero la cues- 
de la compañía obligará inevitablemente a redefinir la compañía y separar realmente ambos planos de la gestión, - - la funcional y la estructural-, para no confundir dos enfoques con fines diferentes y con un tratamiento del valor también distinto: los valores corporativos presentes en la gestión funcional de la marca deben comprenderse de forma diferentes de lo que es una gestión interna de los intangibles y valores de una empresa como organización humana. Hemos visto que la gestión de la marca es fundamentalmente funcional y la llamada gestión estructural está tan determinada por aquella, que la empresa termina secuestrada, —al menos en su comunicación mediática-, por los valores que le asignan las herramientas expresivas de la gestión funcional; circunstancias que dificultan enormemente el conocimiento de la compañía $o$, lo que es peor, distorsionan los verdaderos significados de los valores presentes en la comunicación que se establezca. A mi modo de ver, resulta obligado revisar esta situación en el sentido de redefinir la noción de marca corporativa y trasladar el estudio de los valores y la gestión de intangibles a otro ámbito de las compañías más separado de lo estrictamente comunicativo - comercial o mediático. Esta diferencia explica perfectamente muchas de las acciones de comunicación de las marcas que atienden al producto, al servicio y lo hacen atendiendo a la mejor gestión de los contenidos; sus objetivos son claros y también su alcance y retorno. Pero los límites de estas acciones son temporales, porque el valor tiene otras exigencias y requiere un tiempo que no le permite la acción funcional de la comunicación de marca.

tión es cómo se percibe este hecho en el circuito cognitivo de la marca del que he hecho mención al principio de este artículo.

\section{Las dificultades en la gestión y comunicación del valor}

Por todo lo dicho en el apartado anterior, los modelos de gestión de marcas suponen una herramienta eficaz porque dan forma a la estrategia de marca que, a su vez, debe formar parte de la estrategia de negocio de la compañía (C. Rangel, 2016) ${ }^{9}$; pero me atrevería añadir: pero poco más. Ciertamente es mucho porque deriva de uno de los objetivos primordiales de la compañía que es desarrollar con éxito su modelo de negocio; pero si hablamos de las responsabilidades añadidas de las organizaciones con esto del valor y la ética la cosa es diferente. Resulta del todo cierto, $-\mathrm{y}$ sería del todo injusto por mi parte no reconocerlo-, que hay compañías que están haciendo las cosas bastante bien y que expresan en sus comportamientos el deseo de coherencia, claridad y buen hacer en la gestión de la organización. Pero también hay que decir que esto de la ética es un añadido que distorsiona muchos temas y complica estrategias a la hora de conseguir credibilidad y confianza por parte de las personas que se relacionan con las empresas; porque, en efecto, el valor no puede quedarse en una categoría sino que exige otras precisiones que, como ya he dicho, no cabe reducir a la comunicación comercial al uso. Porque es verdad que gestionando contenidos salen valores, pero si reducimos a éstos a herramientas de comunicación como las que se utilizan, más allá de lo que significa el propio negocio la compañía no genera confianza, si acaso una credibilidad muy del corto plazo. A mi modo de ver aquí reside el

\footnotetext{
9 En este interesante artículo se hace una clara y completa relación de los principales modelos en la gestión de las marcas; algunos más generales y otros más aplicados a acciones puntuales: desde el más conocido de D. Aaker o el delnterbreand, también el de Ollé y Riu, el modelo de John Grant, el del Grupo Young and Rubicam, el de McKinsey o el de Millward Brown y termina con el el modelo de Manuel Martín.
} 
problema que llevo comentando desde el principio y que, en cierto modo, explica la caída libre en la confianza por mucho que las empresas gestionen y comuniquen contenidos y, además, nos hablen de valores. Si mantengo la distinción entre la gestión funcional y la estructural, creo que la marca solo tiene sentido si se gestiona funcionalmente. Por eso no cabe decir que haya gestión estructural de la marca ${ }^{10}$, sino que lo que debe haber además es una gestión estructural de la compañia donde tenga una presencia sustancial la gestión del valor y este trabajo no cabe reducirlo a la marcas corporativa por todo lo que ya he comentado; y aquí entramos en un nuevo ámbito con otras cuestiones y problemas. Es decir; puedo adelantar que las marcas sólo son susceptibles de gestionarse funcionalmente, que la gestión estructural lo es de los valores con los que la compañía se identifica y que están presentes en el conjunto de su comportamiento. Desde esta nueva perspectiva, la marca corporativa solo queda como un referente lejano.

\subsection{El valor en la empresa}

Cuando hablamos de valor en la empresa no estamos hablando del precio de un producto sino que lo estamos haciendo en un sentido moral ${ }^{11}$. Un enfoque que, sin duda en la actualidad, se ha extendido al terreno de la axiología (teoría de los valores) que procura reflexionar sobre el mismo hecho del valor; pero que, en cualquier caso, entiendo no se separa de su preocupación original. Prueba de ello es la constante relación que en la

10 Este es el salto cualitativo y de contenido que doy respecto a lo expresado por mí al final de mi trabajo citado al principio de este artñiculo (J. Benavides Delgado 2013).

11 Incluso I. Kant lo llegó a identificar el valor con la propia moral en su obra de 1785 Fundamentación de la metafísica de las costumbres (he utilizado la traducción castellana de M. García Morente); un texto que escribe cuatro años después de publicar su Crítica de la Razón Pura de 1781. comunicación se hace entre los valores y la gestión ética de una compañía. Pero también hay que decir que cuando comunicamos valores lo que hacemos son juicios de valor; del mismo modo que cuando F. Nietzsche comenzó a hablar de valores lo que hizo fueron juicios de valor, invirtiendo, por ejemplo, los valores de lo bueno y lo malo que se habían dado en la historia europea ${ }^{12}$. A mi modo de ver, la verdadera aportación de Nietzsche fue situar y relacionar directamente el valor con las ideas del mundo y de la vida que tienen las personas. Pero en ambos casos seguimos teniendo el referente inicial de la ética; probablemente el segundo enfoque introduce un aspecto muy interesante porque probablemente es el que hoy afecta al hecho mismo de la comprensión del valor por parte de las personas: el origen y el ámbito de la vida social es la base para la discusión de los significados de los propios valores. Es decir: el valor arranca de la vida misma de las personas y comunicar valores supone expresar formas de ser y modos de comprender la realidad, por eso el valor tiene una indiscutible comprensión moral (J. Benavides 2007, pp. 60 y ss.). Tengamos en cuenta estas breves referencias en los que comentarios que siguen.

Han sido varias las teorías de los valores que se han venido definiendo a lo largo de la historia reciente y han girado desde el extremo de comprender los valores como categorías ajenas a las cosas hasta las perspectivas nominalistas que fundamentan los valores en la subjetividad de las personas y su función instrumental. En cualquier caso parece que existen algunos criterios comunes sobre los valores que, más allá de planteamientos filosóficos, con-

12 Toda su preocupación por los valores fue vertida en numerosos y diversos trabajos que fue publicando en la segunda mitad del siglo XIX, pero probablemente el más importante, dicho por él, fue La genealogía de la Moral (pp.13 y 134 y ss. de la edición castellana de Alianza Editorial, Madrid 1972). 
vergen en lo que aquellos expresan a través del lenguaje y explican los estilos de vida de las personas; en ese sentido los valores expresan determinadas características que deben tener en cuenta: tienen una cierta objetividad (no dependen solamente de las preferencias individuales), jerarquizan categorías y significados (por su propia dependencia respecto a los objetos presentes en la vida cotidiana) y son entidades polarizadas, es decir, se explican polarmente por su contrario. Sin duda el ámbito de los valores se encuentra asociado el hecho mismo del lenguaje y expresan categorías instrumentales y otras muy cercanas a la intencionalidad, los deseos y la opinión de los individuos (M. Scheler, 1941, t. l, p. 235).

Esta cuestión referida a los contenidos de los valores y al modo en que éstos se expresan por parte de las compañías no está en absoluto resuelta: existe una permanente distorsión en los significados de los valores que en muchos momentos quedan reducidos al slogan o a la ilustración de un video o una imagen. Parece cierto que la tarea es complicada, porque no sólo se requiere un análisis y cambio en la mentalidad de los directivos y gestores sino también un cambio de mentalidad en los distintos referentes sociales, Medios de Comunicación y en la propia ciudanía, -normalmente sólo ocupada de sus exclusivos derechos y no de sus derivadas responsabilidades-.
Los valores se pueden clasificar de muy diversas formas; en función de su naturaleza, categorías de oposición (instrumentalidad vs finalidad, individualismo vs colectivismo) o incluso recurrir a enfoques más generales que definen los valores en relación con su posicionamiento objetivo, -posición más cercana a la tradición idealista europea-, o subjetivo; enfoque de origen nominalista $y$ derivado del relativismo lingüístico y cultural del siglo XIX y potenciado por el neopositivismo lógico del principios del siglo XX. En cualquier caso, se puede citar una reciente investigación sobre los valores sociales y la publicidad impresa que clarifica un poco más el panorama (M. D. Gutiérrez Guerrero, 2015, pp. 119-136). Sin duda, la definición de los valores expresados en el Esquema 5 exigen reflexión detallada y solamente vendrá dada por un acercamiento y relación lo más exhaustiva posible con los diferentes grupos de interés con los que se relaciona una empresa y toda su cadena de suministro. Esta tarea no es sólo comunicativa, sino que determinará el debate, la gestión y cualquier otra acción que busque definir la coherencia en los modelos de comportamiento y actividad de una compañía. Los valores referidos en este Esquema 5 tienen sus diferentes derivaciones y jerarquías semánticas desde las que se debe construir el discurso de la compañía y, consiguientemente, el desarrollo de los conteni-

\section{Esquema 5 • Relación de algunos Valores que se deben definir y gestionar en cada caso}

\begin{tabular}{|l|l|l|l|}
\hline Metodológicos & Instrumentales & Polaridad & Finales \\
\hline Transversalidad & Legalidad & Individual/Colectivo & Sostenible \\
\hline Corresponsabilidad & Voluntariedad & Universal/Relativo & Seguridad \\
\hline Subsidiariedad & Transparencia & Racional/Emocional & Verdad \\
\hline Equipo.... & Globalidad.... & Orden /Desorden & Igualdad \\
& & Verdad /Mentira & Felicidad..... \\
\hline
\end{tabular}


dos que deba protagonizar cualquier acción de comunicación donde la compañía sea el principal y único agente. Sin duda hay que tener en cuenta este conjunto de reflexiones para poder entender lo que significa hoy la construcción de un nuevo relato de lo que es y debe ser la empresa13. En este aspecto son diversas las investigaciones que recientemente se están haciendo tanto en el ámbito corporativo como en la investigación académica y universitaria que inciden en la necesidad de que la empresa construya su nuevo relato en el contexto de lo que supone para la compañía compartir Creencias con sus diferentes grupos de interés. (Por ejemplo, C. Fontán 2016, pp. 218 y ss. y 352 y ss.). Desde estas nuevas reflexiones la gestión del valor y el conocimiento se sitúa en la base del cambio de paradigma que deben asumir las empresas y organizaciones en el nuevo ámbito de la globalización y la revolución tecnológica.

Por todo lo que llevo comentando la cuestión del valor es tan compleja y genera problemas de distinta naturaleza. No cabe superar la dificultad de este problema diciendo, por ejemplo, que como la noción del valor es muy complicada es mejor dejar este tema para filósofos y científicos sociales, pero que en los temas de comunicación la investigación va por otro lado. A mi modo de ver, esto es un gran error y puede provocar graves equivocaciones en la orientación de la investigación, cuando defendemos por ejemplo que las marcas deben tener valores o conciencia sin más explicaciones que añadiendo un conjunto de calificativos a nuestros argumentos comerciales; el tema tiene mucho más fondo. Como acabo de decir esto de la ética genera muchas cuestiones y no pocos problemas que hay que pensar e investigar en profundidad y no quedarnos en un buen slogan o en una creativa ocurrencia.

13 Ver también otros textos en las Referencias Bibliográficas.
A mi modo de ver, -y dada la obligada brevedad de este artículo-, se pueden distinguir dos posibles enfoques que ayuden en la claridad de estas cuestiones. El primero de ellos hace referencia el papel del valor, lo que éste significa y aporta en el modo de gestionar una compañía y el segundo enfoque se concreta en el espacio social que ocupa la comunicación del valor que no es otro que el contexto de los Medios de Comunicación. Son dos enfoques, —casi de método-, que sólo pretenden ubicar la reflexión sobre la comunicación y gestión del valor. Dedico unas breves reflexiones a estos dos enfoques. Simplifico enormemente las consecuencias de la gestión del valor en las empresas porque, como acabo de comentar, alargaría mucho este artículo. Me limito a enmarcar las principales cuestiones.

\subsubsection{El rol del valor}

Respecto al primer enfoque, entiendo que el hecho del valor en la empresa no puede separarse de lo que significa la globalización y el desarrollo tecnológico ${ }^{14}$. Lo que realmente supone la globalización, —-tanto económica como cultural—, es un cambio profundo y estructural en el contexto de las organizaciones e instituciones sociales (grandes y pequeñas); y ese cambio se soporta fundamentalmente en una nueva forma de entender la realidad del valor, en una mentalidad que asume que cuando hacemos juicios de valor estamos intercambiando un conocimiento plural den el ámbito de la cultura. El valor se conoce y comunica a través de la vida misma. Por ello, a la hora de integrar la noción de valor o hacer juicios de valor lo que se debe atender en el seno de la organización es lo que supone y exige éste conocimien-

14 Me refiero desde los aspectos de la globalización que afectan a los contextos económicos, culturales y sociales hasta los que derivan de la gestión de los Big Data provocada por el desarrollo de la tecnología. 
to en el ámbito de su gestión y comunicación. Porque esa cuestión y no otra, _el hecho de que el valor construye y es conocimiento_- es lo que ha venido a cambiar las preocupaciones y formas de comunicación de la identidad de las compañías y su finalidad en la sociedad, más allá del modelo de negocio y la comunicación de la marca. Por ello, el ser y la comunicación de los valores de una empresa no puede distanciarse de lo que significa la gestión y transmisión de conocimiento. Esta es la verdadera novedad que experimentan en la última década y a nivel global las compañías y el conjunto de las instituciones sociales.

Ya hemos visto que, en un primer momento, los valores parecieron situarse en un ámbito de trabajo que en su origen parecía resuelto con lo de los intangibles asociados a la marca corporativa y luego con el tema de la comunicación global y transversal de la compañía a través de una Dirección de Comunicación que unifica y globaliza todas sus acciones comunicativas. Pero en el medio plazo esta situación confunde porque, en efecto más allá del negocio, después de más quince años de trabajos y comportamientos corporativos y el propio desarrollo de las tecnologías digitales, se han descubierto los cortos fundamentos de algunas acciones de comunicación acometidas por las compañías en esto de la creación de confianza y la seguridad en la conformación de las estrategias más adecuadas. El estudio del valor y los contenidos a él asociados no parecen depender solamente del Director de Comunicación ${ }^{15}$ sino que parecen necesitarse otros perfiles profesionales $y$, sobre

\footnotetext{
15 Hace más de veinte años la figura del Director de Comunicación empezaba a suponer, - lo que de hecho sucedió a los pocos años-, un cambio en la manera de comprender la comunicación de la empresa y, lo que es si cabe más importante, una transformación profunda en lo que empezaba a significar la comunicación: una nueva forma de gestionar el conocimiento y no sólo una forma de trasladar información (J. Benavides Delgado, 1992). En el momento presente parece estar sucediendo algo parecido, pero no en lo que respecta al DIRCOM sino
}

todo, nuevos conocimientos y quehaceres que, hasta hace poco, no existían en el imaginario empresarial16 (C. Bazán, J. de la Morena \& H. Cortés, 2016, pp. 348 y ss.). Es decir; el momento presente de crítica y exigencia social exige nuevos enfoques y, sobre todo, actitudes y formas de pensar que normalmente no se contemplaban en las compañías y organizaciones. No es un cambio exclusivo de herramientas o de nombres sino de paradigma (J. L. Fernández, J. Benavides Delgado, R. García-Polo \& F. Sánchez-Mora, 2014, pp. 35-57).

Sin duda, esta situación de incertidumbre se ha puesto de manifiesto en el universo corporativo y, como ya hemos visto en su inicio, fué aterrizando en la comunicación de las marcas; lo fue hace ya algunos años con el desarrollo de la marca corporativa y lo es ahora con los temas relacionados con los nuevos perfiles profesionales como los expresados por el papel del DIRSE o de los CCO en las grandes compañías. En efecto, parece que el nuevo perfil profesional se enfrenta con temas, -algunos inéditos en la gestión de la empresa-, que exigen afrontar cuestiones alejadas aunque relacionadas con el modelo de negocio y los nuevos compromisos sociales de las compañías. Con el tema del valor el gestor empresarial se encuentra situado frente a un conjunto de nuevas relaciones y de una transversalidad en su gestión que casi exige una nueva mentalidad en el empresario y en el conjunto de los empleados y diversos grupos de interés con los que interactúa la organización; una mentalidad que abre nuevas áreas de contenidos, donde la marca no tiene por qué está presente y donde la comunicación tiene también su papel. Desde ese contexto, se debe profundizar en lo que significa el deber de hacer bien las cosas;

en lo que se refiere a nuevos perfiles profesionales que deben responder a los propios compromisos y exigencias sociales. 16 Utilizo a algunos de mis comentarios vertidos en el texto de estos autores. 
una cuestión que no se dilucida haciendo buenos insgihts publicitarios sino construyendo una manera de internalizar significados y de actuar de modo ejemplar y coherente.

Finalizado el curso pasado publiqué un conjunto de conclusiones en relación con la gestión del valor de la RSE en las compañías ${ }^{17}$; dichas conclusiones pueden aplicarse perfectamente al tema que llevo comentando en la gestión del valor en la empresa. Son conclusiones que pueden observarse casi exclusivamente como tareas que, a mi modo de ver, deben atender los gestores del valor en la organización. (J. Benavides Delgado, 2016, p. 249 y ss.).
Como hemos visto, en el estudio del valor, al igual que sucede con la RSE, aparecen un conjunto de tareas fundamentales que tienen las organizaciones como obligación inexcusable. Lo indicado en el Esquema 6 se concreta en tres áreas fundamentales con sus consecuencias en la comunicación y su consiguiente reflejo en la gestión y resultados de la expresión de la compañía como cadena de valor. En efecto, estas áreas de trabajo siguen abiertas al debate y la investigación y, a mi modo de ver, no están resueltas en el universo corporativo. Sin duda, la globalización de la información ha venido a multiplicar de forma exponencial este conjunto de contenidos.

\section{Esquema 6 - Las exigencias del valor como conocimiento en la gestión y comunicación de las compañías}

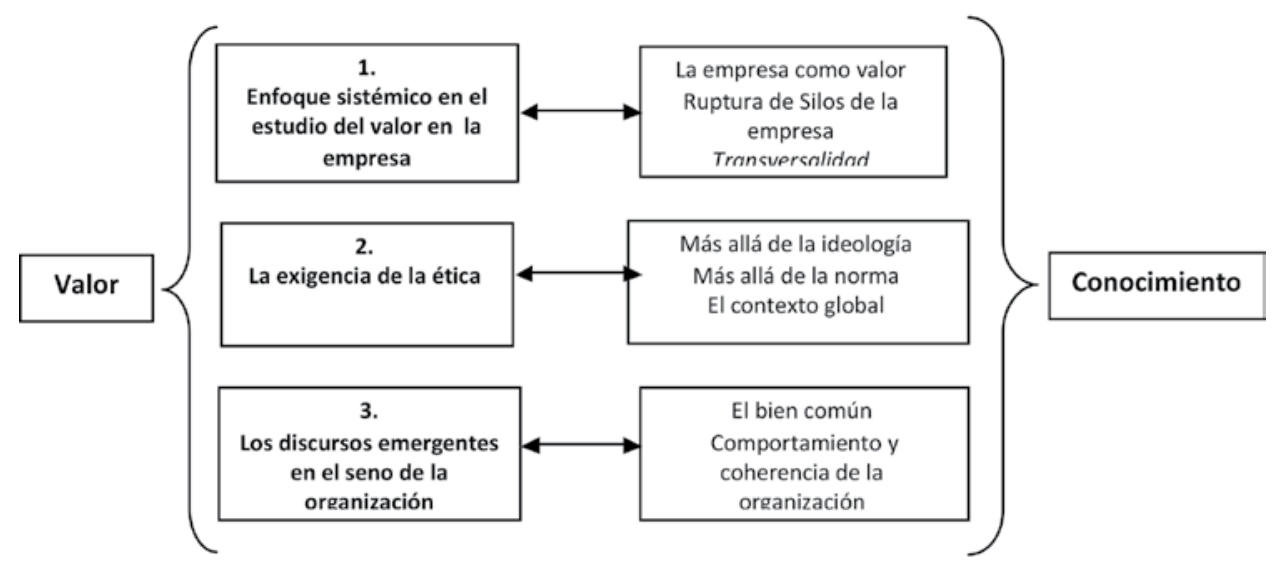

17 Fruto de nuestros trabajos en la Cátedra de Ética Económica y Empresarial de la U. P. Comillas de Madrid.
Las resumo muy brevemente.

En primer lugar, parece fuera de toda duda que el valor exige de las organizaciones un nue- 
vo relato que requiere un enfoque de estudio abiertamente pluridisciplinar y que he dado en definir, al principio de este artículo, como enfoque sistémico. En el contexto de este tema aparecen dos fundamentales niveles de problemas que afectan directamente a la propia noción de valor que se asuma y sus ámbitos de significado derivados; concretamente:

- El hecho de que el valor de la empresa está por encima de los valores que presumiblemente se asocian a los productos y servicios de la compañía. Las compañías deben crear una nueva relación entre los valores de sus marcas y lo que significa el papel fundamental del valor de una organización en el contexto social donde aquella opera. Son dos niveles que se relacionan pero con objetivos y contenidos distintos. Esta realidad exige de los directivos y del conjunto de los grupos de interés de la organización una nueva responsabilidad sobre las consecuencias de sus propias decisiones. Así por ejemplo, el origen de un negocio no puede limitarse a su exclusiva viabilidad económica en el corto o medio plazo, sino en el retorno social que dicho proyecto pueda tener en el medio y largo plazo. De lo contario puede suceder que la determinación del modelo de un negocio se desarrolle incluso desde un fraude social en origen al no entender debidamente a las consecuencias de lo que se está haciendo. Ganar mucho dinero en el corto plazo,
— como ha sucedido en algunas proyectos del entorno tecnológico- solo ha expresado la determinación exclusiva del modelo de negocio sobre un proyecto empresarial que debería centrarse en el valor. La gestión del valor exige distanciar definiciones y objetivos en un proyecto y saber ponerlos en relación y especialmente saber determinar qué está por encima de qué (Ver Esquema 7).

- La necesaria transversalidad que debe adoptar la empresa en relación con el blindaje e impermeabilidad tradicional de los departamentos y silos que la constituyen.

En segundo lugar, la ética tiene una importantísima presencia, tanto en sus redefiniciones como en las exigencias y consecuencias a las que conduce su estudio en lo que respecta al valor; frente al emotivismo moral, tan presente en la sociedad actual, la ética debe buscar un cierto consenso universal que supere las ideologías y las normas internas de una compañia, —normalmente formuladas desde contextos culturalmente más locales- La globalización empieza a exigir universalización de contenidos y este proceso tiene consecuencias importantes en el estudio del valor.

En tercer lugar, resulta imprescindible un estudio de los contextos emergentes de los discursos sobre los valores; en definitiva, conocer los ámbitos de significado, los espacios topológicos del lenguaje que se utilizan en la empresa. $L a$ organización no sólo debe potenciar su modelo de

\section{Esquema 7 - La determinación del valor en la gestión de la empresa}

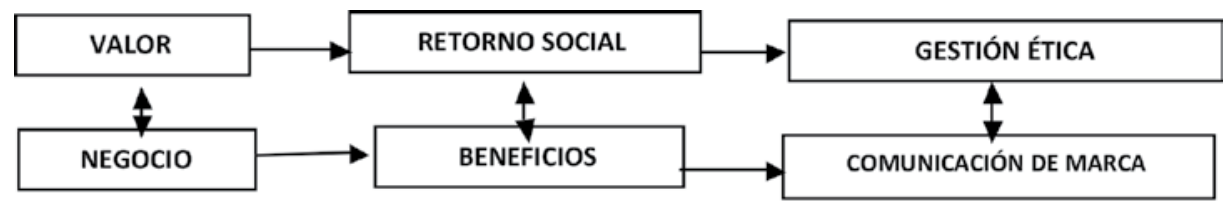


negocio, sino aquellos valores que se convierten en los contenidos reales de su gestión, comunicación y modo de ser y estar como compañía en una sociedad; estos valores son los que deben ponerse en relación con lo que significa la gestión del bien común, que es en definitiva el objetivo central de cualquier organización (Ver Esquema 7).

\subsubsection{El espacio social del valor}

La segunda dificultad que tienen las empresas y organizaciones de gestionar el valor es el propio entorno social que ocupan. Un contexto muy construido por los Medios de Comunicación y las propias instituciones y grupos sociales. Este entorno supone un constructo de espacios sociales, normalmente artificiales y cambiantes en el corto plazo, y determinados por unos lenguajes en ocasiones vacíos de contenido,- incluso de sentido-. Por ello mismo, las organizaciones deben tener en cuenta éstos entornos donde operan y se comunican con sus marcas y evitar en lo posible la banalidad diletante, muchas veces la nada cultural que habita en estos espacios sociales (J. Benavides Delgado, 2017). Porque, en efecto, el entorno social que rodea a las organizaciones puede suponer un serio obstáculo para la comprensión de lo que es el valor y de lo que hacen y deben hacer las compañías. A mi juicio, las empresas deben ser conocidas de modo correcto y adecuado, deben ser exigidas en su coherencia y transparencia, pero no deben ser dependientes de los Medios como muchas veces sucede, porque esa dependencia simplifica los problemas y los reduce a una cuestión de terminología y de palabras. No se olvide que cuando todo se queda en palabras o imágenes se olvidan los significados; porque aquellas cambian y éstos son los que permanecen en las acciones y los comportamientos que se hacen cada vez más ocultos. Las organizaciones son gobernadas por personas y el significado del valor se concreta y desarrolla en las personas no en el constructo que se pueda hacer de sus modelos de gestión y comunicación. En el fondo, esa diferencia es la que me ha llevado precisamente a separar la gestión de la marca de la gestión del propio valor en la organización.

En el contexto de los Medios de Comunicación y de la propia sociedad en el contexto general de la revolución tecnológica, la globalización y la consiguiente convivencia y pluralidad de culturas multiplica, por un lado, las racionalidades con las que las personas y los grupos sociales comprenden la realidad; más todavía, esas racionalidades han sido normalmente construidas por los Medios. Por otro lado, la globalización tiende a universalizar y homogeneizar unas racionalidades sobre otras. Cuando esta homogeneización produce crisis y retrocesos, las culturas locales desarrollan actitudes de rechazo y una especie de individualismo populista que puede conducir inevitablemente a la segmentación y empobrecimiento de esos territorios y de la propia sociedad en su conjunto (J. Benavides Delgado, 2016, p. 252). Este es el turbulento entorno social de las organizaciones que, como ya he indicado, constituye un problema añadido en la gestión y comunicación del valor en las organizaciones.

No cabe duda que se han hecho esfuerzos encomiables y meritorios, expresados en los informes y libros que se van publicando día a día. En algunos de ellos quedan muy bien reflejadas las áreas que deben trabajarse en esto del valor; se observan ideas muy claras y bien definidas. Por ejemplo, en el Informe ya citado al principio de estas páginas Approaching the -Future. Informe de tendencias en gestión de intangibles se ofrece una buena clasificación de las áreas que actualmente preocupan en el seno de las compañías; concretamente cuatro: tendencias glo- 
bales, sostenibilidad, reputación y gobierno corporativo. Es verdad que algunas de las clasificaciones desarrolladas en cada uno de los apartados son más precisas que otras, pero al menos sirven de guía y ejemplo (Approaching the Future, 2017, pp.32-33). logo- entre el ámbito de lo construido y el ámbito de lo real. Pues bien; el contexto de lo construido pertenece principalmente a lo estructural: a la gestión de la ética y las exigencias sociales donde el valor en la empresa tiene especial protagonismo. Por el contrario el contexto de lo real

\section{Esquema 8 - Divergencia entre la realidad y lo que se dice sobre ella}

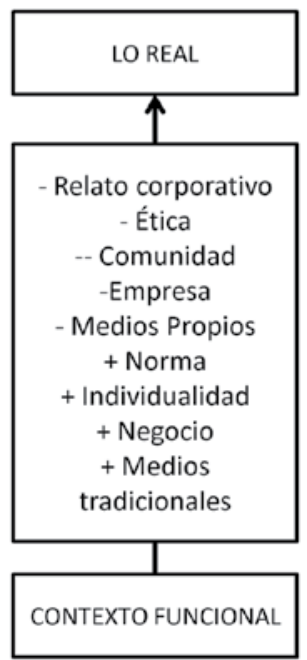

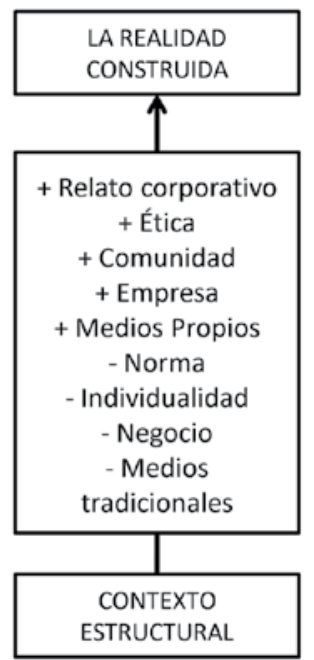

Esquema 7. En el contexto de los Medios y muchas veces el lenguaje utilizado por ellos y los propios ciudadanos desvirtúa lo que debe hacer la empresa en la gestión del valor y la sustituye por una realidad construida artificialmente que no existe. Se dice una cosa (lo real construido y deseado) pero se hace otra (lo real). El contexto funcional de la comunicación prevalece sobre el ámbito estructural de lo que la empresa debe ser.

Sin embargo, la dificultad no desaparece. Habría que observar la diferencia que se puede establecer entre lo que se dice y lo que se hace. Por ejemplo, en el Esquema 7 hago una distinción -una distinción aconsejada por un amigo psicó- pertenece a la comunicación de la marca y a la preocupación permanente por el modelo de negocio $^{18}$. Si se observa el papel determinante que cumplen los Medios de Comunicación y las propias instituciones políticas y sociales podemos observar la dificultad con la que se enfrentan las empresas a la hora de comunicar el valor y sus modelos de comportamiento derivados: o que no dicen la verdad o que no la pueden decir. Muchas veces las empresas, -al igual que los Medios de Comunicación, nos hablan desde el con-

18 Muchas de los debates que observamos en los Medios de Comunicación y en lo discutido en los Informes de las propias compañías expresan este maniqueísmo. Se habla de una manera y se actúa de otra. Por eso mismo, la credibilidad en el sistema desciende. 
texto estructural que es lo que exigen los cambios y la propia sociedad, pero hacen lo que exige el contexto funcional de la realidad comercial. Muchas empresas dicen una cosa pero hacen inevitablemente otra muy diferente; algunas procuran definir modelos ejemplares de actuación con sus grupos de interés, pero luego se ven incapaces de desarrollar dichos modelos. Los entornos sociales no siempre son propicios, la moralidad de sus propios gestores no es, quizá, la más adecuada o la falta de decisiones políticas a nivel global sirven de permanente cobertura. Esta realidad a veces es tozuda.

A mi modo de ver, este es un problema generado por la propia globalización mediada y que afecta a la gestión de la marca y muy especialmente a la gestión del valor en la empresa. La marca es un signo de representación, la conciencia y la ética reside en las personas no en las normas; por ello lo importante de una compañía, - como de una institución o de un partido político y por encima de su propia ideología—, es la moralidad de sus gestores y del conjunto de sus grupos de interés. A mi modo de ver, y a modo de ejemplo, la marca no tiene ni puede tener conciencia, es tan sólo un signo que representa algo, una manera de comunicar. Por ello si todo el mundo entiende las afirmaciones que se hacen desde la marca es porque las personas las interpretamos como un insight creativo; nada más. Lo verdaderamente importante reside en el propio contenido, en lo que éste significa expresado en los comportamientos reales que pueden ser contradictorios o incoherentes y no en el discurso ficticio que genera en la sociedad; porque lo más normal, _lo que casi siempre sucede_-, es que el contenido quede reducido a simples palabras que no expresan lo que demandan sus significados y lo que debe ser el comportamiento de la empresa o de la organización de que se trate.

\section{Conclusiones}

Parece claro que la globalización está planteando nuevos problemas que es necesario vertebrar. Los directivos de las empresas y las organizaciones deben aprender a pensar el mercado y la sociedad de otra manera; deben de dejar de decir cosas nuevas y, al tiempo, seguir haciendo lo mismo. Este es el verdadero reto del siglo XXI: nuevos lenguajes, nuevas rutinas que impidan a las organizaciones e instituciones sociales avanzar con los empujones de la moda.

A mi modo de ver, la dificultad de este artículo radica en encontrar el lugar de los problemas. Lo he procurado, pero desconozco si con éxito. La dificultad de lo que significa diferenciar la comunicación de la marca y la gestión del valor en las organizaciones es el eje central de todo el conjunto de mis reflexiones; es una distancia que entiendo debe producirse porque la comunicación de las organizaciones está sujeta y se mueve en un contexto de turbulencia, cambios y artificialidad donde es inevitable estar pero donde no siempre es aconsejable. Estas circunstancias provocan desencuentros y en muchas ocasiones posiciones maniqueas entre lo que se dice y lo que se hace; porque se dice lo que debe decirse y se hace lo que, a lo mejor, no es deseable pero si inevitable: el constructo artificial prevalece sobre lo que realmente sucede. Situación que explica la caída en la confianza y el crecimiento de la inestabilidad y la inseguridad en la era de la globalización. Todo ello es el resultado de un proceso que he venido comentando y que me atrevo a simplificar en los siguientes pasos:

4.1. A mi modo de ver, la marca debe abandonar viejas tipologías y centrarse en su modelo de gestión más extendido, quizá el único, que he dado en llamar gestión funcional de la marca. Su objetivo y retorno prioritario es el modelo de negocio. La difi- 
cultad de este proceso consiste en la naturaleza cognitiva del complejo circuito que recorre la marca; un proceso extremadamente sutil y complejo que afecta a muy diversos referentes y espacios sociales. Sin embargo este tipo de gestión es fácil y sencillo porque su lenguaje es claro, preciso y con conocido retorno: acciones promocionales, campañas de comunicación publicitaria comercial, patrocinios corporativos, etc.

4.2. En el ámbito de este proceso la marca no sólo se ayuda de servicios y objetos reales, sino sustancialmente de categorías de valor que dirigidos al desarrollo creativo de contenidos persiguen el contacto emocional con los individuos y el conjunto de los grupos sociales. Desde estos objetivos la gestión de la marca construye sus principales estrategias de comunicación. Este proceso comunicativo, ayudado por las nuevas herramientas y dispositivos que aporta la revolución tecnológica, se multiplica exponencialmente produciendo saturación y homogeneidad en la gestión de la marca.

4.3. La saturación en la gestión de la marca requiere diferenciación y por ello la marca persigue enriquecerse con nuevas categorías de valor que procuran introducir en el circuito de las marcas a lo representado por ellas mismas: la propia compañia. Sin duda los valores corporativos de la marca y el propio sector donde opera la empresa cobran especial protagonismo en dichos procesos de diferenciación. Con este último proceso las marcas introducen de una forma definitiva el valor, que ya no se asocia exclusivamente con el producto o los estilos de vida sino con la propia empresa.

4.4. Sin embargo la gestión de estos nuevos valores relacionados con la empresa complican el proceso funcional de la marca porque requieren nuevas precisiones de contenido asociadas no sólo a lo que las marcas objetivan de cara a su modelo de negocio, sino al comportamiento de sus directivos y diversos grupos de interés que constituyen la empresa. Con los valores se ha introducido en las compañías nuevas preocupaciones y objetivos que exigen otras formas de hacer y de decir las cosas.

4.5. Estas circunstancias se han complicado por los propios procesos de globalización, que obligan a las empresas a comprender que la comunicación de los valores ya no supone una comunicación avalada por los valores del producto ni siquiera de la propia empresa reducida a un conjunto de categorías e imágenes (como si fuera un producto), sino una comunicación que defina y gestione una forma de conocer la empresa: el valor es conocimiento. Sin embargo, la mayoría de las empresas han optado por seguir utilizando dichas categorías de valor como herramientas publicitarias, convirtiendo los valores en un instrumento para demostrar la compañía se comporta bien con la sociedad (acciones sociales, patrocinios corporativos, etc.).

4.6. Esta opción, sin embargo, profundiza la desconfianza social y genera contradicciones y opacidad en el propio lenguaje utilizado por las empresas. Los valores requieren más profundidad en lo que éstos significan. En efecto, con los valores se introducen en la compañía nuevas disciplinas y responsabilidades que no pueden quedar explicadas en puntuales acciones de comunicación; por lo cual, muchas compañías se dedican a la preparación y redacción de informes que trasladan a la sociedad a través de presentaciones, mayormente tuteladas por los Medios de Comunicación. 
4.7. Con el valor se debe sustituir o, si se quiere, superar la gestión funcional de la marca, porque la compañía requiere nuevas herramientas que debe arbitrar y nuevas cuestiones que debe dilucidar a la hora de la toma de decisiones tanto en la gestión como en la comunicación de su empresa. Paralelamente, las instituciones públicas, -a nivel nacional e internacional-, y la propia ciudadanía participan de una progresiva información que les hace exigir a las compañías una mayor responsabilidad en sus modos de hacer y sobre todo de comportarse. Circunstancia que complica si cabe un poco más la ya compleja situación del conjunto de las organizaciones porque saber definirse incluso dependerá también de las propias decisiones políticas.

4.8. Con todo este conjunto de procesos mutuamente relacionados, las organizaciones deben distinguir lo que significa la marca y su gestión de lo que significa el conocimiento del valor, sus exigencias éticas y adecuada transmisión que no cabe reducir a las herramientas tra- dicionales de la comunicación comercial. De lo contrario se pueden producir contradicciones e incoherencias que es lo que habitualmente sucede. Esta situación de indefinición se complica todavía más con la intervención y el propio papel de los Medios de Comunicación, que al igual que en la gestión funcional de la marca, tiene un protagonismo decisivo en el ámbito del propio mercado. Es muy posible que el papel de los Medios de Comunicación no siempre aclare lo que de hecho sucede en el ámbito de las empresas y organizaciones; puede suceder que construyan un discurso sobre las empresas y corporaciones que no siempre coincida con la realidad de los hechos.

4.9. En la base para la comprensión de todo este conjunto de procesos de definición y cambio se debe situar la moralidad de los propios gestores, directivos y de los diversos grupos de interés de la organización; moralidad, sin la cual resultará imposible llevar adelante los cambios que exige la realidad social y una globalización más humana y justa. 


\section{Bibliografía}

Aaker, D., (1991) Gestión del valor de marca, Díaz de Santos, Madrid.

(1996) Measuring brand equity across products and markets, California management Review, 38, 3, pp. 102-119.

(2004) Construir marcas poderosas, Comunicación 2000, Barcelona.

Benavides Delgado, J. (1992) El director de comunicación: un planteamiento para la investigación universitaria en Director de Comunicación, Control, Madrid., pp. 143-156.

(2007) La comunicación de los valores en las empresas y organizaciones en Evolución conceptual y práctica de una gestión responsable. Memoria Académica Curso 2006-2007 (A. Bajo \& N. Villagra, eds.), Universidad Comillas, Madrid.

(2013), Un nuevo enfoque para la comprensión de la marca y la comunicación de la empresa en Prospectivas y tendencias para a comunicación en el siglo XXI, CEU Ediciones, Madrid, pp. 515-543.

(2015), La publicidad, la marca y la ética en la construcción de los valores sociales en Comunicación y empresa responsable (J. Benavides \& A. Monfort, eds.), Eunsa, Pamplona, p. 45-58. (2016), La responsabilidad Social. Cuestiones de fondo pendientes de estudio en Los condicionantes al desarrollo de la responsabilidad Social Empresarial. Memoria Académica Curso 20152016 (A. Bajo, N. Villagra, eds.), Universidad P. Comillas, Madrid, pp. 233-253.

(2017), El contexto de los medios y la nueva racionalidad (en prensa).

Carreras, E., Alloza, A., \& Carreras, A., (2013). Reputación Corporativa. Madrid: LID Editorial Empresarial.

Corporate Excellence.

(2012). La reputación corporativa, factor cada vez más importante en la decisión de compra de productos. Madrid.

(2015a). Identidad corporativa: cómo las compañias líderes definen, activan y alinean sus valores corporativos con la estrategia global de la organización. Madrid.

(2015b). La comunicación corporativa hoy, en el marco de un entorno mucho más complejo, cambiante y global. Madrid.

(2015c). Identidad corporativa: cómo las compañias líderes definen, activan y alinean sus valores corporativos con la estrategia global de la organización. Madrid.

(2015d). La comunicación corporativa hoy, en el marco de un entorno mucho más compl ejo, cambiante y global. Madrid. (2016a). Reputación corporativa, el resultado de una cultura de valores compartidos. Madrid.

(2016b) Marcas con conciencia. Madrid.

Costa, J., (2013). Los 5 pilares del branding: anatomía de la marca. Costa Punto Com.-

(2015). El Paradigma Dircom. Costa Punto Com.

Fernández Fernandez, J. L. (2015). El capitalismo. ¿Bastan las leyes del mercado para regular la economía?, Digital Reasons, Madrid.

Fernández Fernández, J. L., Camacho, I., González, R., \& Miralles, J., (2013). Ética y responsabilidad empresarial. Bilbao: Desclee De Brouwer

Fontán Gallardo, C., (2016), Propuesta de modelo para la construcción de la estrategia narrativa corporativa, Tesis Doctoral, Universidad Complutense de Madrid (inédita).

Freemann, R.E., (1984). Strategic management: A stakeholder approach, Pitman., Boston.

Friedman, M. (1970), The social responsibility of business is to increase its profits. The New York Times, 122-124.

Fombrun, C., Gardberg, N. \& Sever, J.M., (1999). The Reputation Quotient: a multi-stakeholder measure of corporate reputation. The Journal of Brand Management, 7(4) pp. 241-255

Fombrum, C., Ponzi, L. \& Gardberg, N., (2011). Conceptualizing and Validating a Short-Form Measure of Corporate Reputation. Corporate Reputation Review, 14(1), pp. 3-14.

Fombrun, C. \& Van Riel, C., (2004), Fame \& Fortune: How Successful Companies Build Winning Reputations, Financial Times Prentice Hall, Nueva York.

García Bautista, S.N. (2016) Propuesta de una hoja de ruta para la marca país. Del concepto del marketing al concepto de reputación. Tesis doctoral, Universidad Complutense de Madrid, Madrid (inédita).

García, S. \& Dolan, S. (1997). Dirección por valores. Madrid: McGraw-Hill

Giner, S., (2012) El origen de la moral. Ética y valores en la sociedad actual, Península, Barcelona.

Gutierrez Guerrero, M. D. (2015), Lenguaje y valores sociales en publicidad impresa, Tesis Doctoral, Universidad de Málaga (inédito). 
Hatch, M.j. \& Schultz, M., (2008) Esencia de Marca, Ed. Lid., Madrid.

Ind, N. (1998). An integrative approach to corporate branding, en «Journal of Brand Management», 5(5), pp. 323-9.

Ind, N., Iglesias, O. \& Schultz, M., (2013). Building brands together: Emergence and outcomes of co-creation, en «California Management Review», 55(3), pp. 5-26.

Interbrand, Foro de Marcas Renombradas Españolas (2008), El glosario de las marcas. Madrid: LID Editorial.

Jenkins, H., (2008). Cultura de la convergencia, Paidós, Barcelona.

Kant, I. (1785), Fundamentación de la metafísica de las costumbres, Austral (3a ed.), Madrid 1946.

Kapferer, Jean-Noël (1992): La marca, capital de la empresa. Bilbao, Deusto.

Kapferer, Jean-Noël (1997): Strategic Brand Management. Creating and sustaining brand equity long term. Londres, Kogan Page.

Kapferer, Jean-Noël (2012): The new strategic brand management. Advanced insights \& strategic thinking. Philadelphia, Kogan Page.

Kapferer, Jean-Noël y Thoenig, Jean-Claude: La marca.Motor de la competitividad de las empresas y del crecimiento de la economía. Madrid, McGraw-Hill.

Keller, Kevin Lane (1993): «Conceptualizing, Measuring and Managing Customer-Based Brand Equity». Journal of Marketing, n. 57 (January), pp. 1-22.

Koselleck, R., (2012). Historias de conceptos. Estudios sobre semántica y pragmática del lenguaje político y social, Ed. Trotta, Madrid

Mañas Viniegra, L. (2017) La construcción del valor de marca. Análisis de Real Madrid como World Class- Brand, Tesis Doctoral, Universidad Complutense de Madrid, Madrid

Nietzsche, F., (1972) La genealogía de la moral, Alianza Editorial, Madrid.

Rangel Perez, C., (2013), La nueva gestión de las marcas. Una visión en el sector del lujo, Tesis Doctoral, Universidad Complutense, Madrid (Inédita)

(2015) Claves para elegir un modelo de gestión de marcas, «Revista Internacional de Investigación en Comunicación aDResearch» ESIC. No. 11, Vol 11. págs. 40-57.

Riel, C.B.M., van, (1995) Principles of Corporate Communication, Prentice Hall, London.
(2012) Alinear Para ganar, Lid Editorial, Madrid.

Ries, Al y Ries, Laura (2000): Las 22 leyes inmutables de la marca. Barcelona, McGraw-Hill.

Ries, Al y Ries, Laura (2005): El origen de las marcas. Barcelona, Empresa Activa.

Scheler, M. (1941), Ética (2 tomos), Revista de Occidente, Madrid.

\section{Varios autores}

(1992) Director de Comunicación (J. Benavides Delgado, eds.), Control, Madrid.

(2004), Ética y globalización (Vicente Serrano, ed.), Biblioteca Nueva, Madrid.

(2008), Moral Markets. The Critical Role of Values in the Economy (P.J. Zak, eds.), Princeton Universiy Press, Oxford.

(2011), Globalización y responsabilidad. Claves éticas de la mundialización (Fco. J. Roa et. al), Every View Eds., Madrid. (2014), Repensar la responsabilidad social, Una mirada desde los Dirse, (J. L. Fernández, J. Benavides Delgado, R. GarcíaPolo \& F. Sánchez-Mora), Madrid.

(2015) Observatorio de la Publicidad 2014. La comunicación en cambio permanente (J. Benavides, D. Alameda, E. Fernández, C. Lopez \& J. Sánchez), Asociación Española de Anunciantes, Madrid.

(2016a) Observatorio de la Publicidad en España 2015 (J. Benavides, D. Alameda, E. Fernández, C. Lopez \& J. Sánchez), ESIC, Madrid.

(2016b), Estudio de las variables utilizadas por los anunciantes en su relación con los medios, (J. Benavides, D. Alameda, E. Fernández, C. Lopez \& J. Sánchez), ESIC, Madrid.

(2016c) Media and digital predictions, Cantar Millward Brown.

(2016d) El impacto de los profesionales en el fomento de la reputación. ¿Cómo medirlo y cómo activarlo?, Alcor \& Corporate Excellence, Madrid.

(2016e), Marcas con conciencia. Los grupos de interés exigen marcas éticas y humanas, Corporate Excellence, Madrid.

(2016f), Guía para la integración de la Responsabilidad Social corporativa (C. Bazán, H. Cortés \& J. de la Morena), Bosch, Wolters Kluwer, Barcelona. 
(2016g), Brands with a Conscience: How to Build a Successful and Responsible Brand (Ind, N. \& Horlings, S.,eds), Londres: Kegan Page.

(2017a) Los nuevos caminos de la marca (J. Benavides Delgado, Coord.), Fragua, Madrid. (2017b) Approaching the Futur. Informe de tendencias en gestión de intangibles, Corporate Excelence, Research Centre of Governance, Sustainability and Reputation

2017c) Reputación y valor añadido, Lorente y Cuenca, Madrid. 